\title{
Eins nach dem anderen
}

_ Die bayerische Kabarettistin Monika Gruber fordert in ihrem aktuellen Programm „Hauptsach' g'sund“ ihre Zuschauer mit einem Augenzwinkern auf, sich folgende Situation vorzustellen: Ein Mann bindet sich seine Schnürsenkel, während seine Ehefrau ihm eine Frage stellt. Was wird passieren? Er wird für die Antwort absetzen müssen, ist Gruber überzeugt. Und hat mit dieser klischeehaften Pointe die Lacher der Frauenwelt garantiert auf ihrer Seite.

_ Dass allerdings Männer und Frauen im Multitasking gleich schlecht abschneiden, belegt eine Ende Juni erschienene Untersuchung des Instituts für Arbeit und Gesundheit der Deutschen Gesetzlichen Unfallversicherung. Die Forscher haben herausgefunden, dass sich die Leistungen der 64 Probanden durch Multitasking verschlechterten, sie angespannter waren und ihre Herzen schneller schlugen - und zwar unabhängig von Geschlecht und Alter (॰ www.risiko-raus.de).

_ Multitasking ist heutzutage zum Normalzustand geworden. Sicherlich fallen Ihnen auf Anhieb unzählige Situationen aus Ihrem beruflichen Alltag ein, die Sie regelmäßig zur Multitaskerin machen. Sie schreiben zum Beispiel gerade konzentriert einen Therapiebericht und mittendrin klingelt das Telefon und eine Klientin möchte den Termin verschieben. Während Sie auflegen, flitzt schon das nächste Therapiekind durch die Praxis, spitzt bei Ihnen ins Büro und will bereits loslegen. Die Kollegin fragt im Vorbeigehen, ob sie in der nächsten Einheit den Motorikraum nutzen kann. Und im Hinterkopf wartet noch eine riesige To-do-Liste, die Sie nach Feierabend erledigen sollten.

\begin{tabular}{|c|c|}
\hline \multicolumn{2}{|l|}{ ZU GEWINNEN } \\
\hline \multicolumn{2}{|l|}{ Kursplatz } \\
\hline \multicolumn{2}{|c|}{$\begin{array}{l}\text { Einführung in das Ergothera- } \\
\text { peutische Assessment } \quad \text { Seite } 45\end{array}$} \\
\hline \multicolumn{2}{|l|}{ Bücher } \\
\hline \multicolumn{2}{|c|}{ 3-mal Reiseführer „Los Angeles } \\
\hline \& Südkalifornien“" & Seite 32 \\
\hline 3-mal „Multitasking“ & Seite 30 \\
\hline \multicolumn{2}{|c|}{ 3-mal „Fallbuch Ergotherapie } \\
\hline \multicolumn{2}{|l|}{ und außerdem } \\
\hline \multicolumn{2}{|c|}{1 Freikarte für den ergotag Seite 35} \\
\hline 1 Gesundheitskissen & Seite 51 \\
\hline \multicolumn{2}{|c|}{ 2-mal je 2 Paar Socken für die } \\
\hline Fußreflexzonenmassage & Seite 51 \\
\hline 2-mal Übungskarten & \\
\hline „Der aufrechte Mensch“ & Seite 51 \\
\hline 1 Buchgutschein & Seite 6 \\
\hline
\end{tabular}

_ Was tun? Immer schön eins nach dem anderen, so die Botschaft unseres Artikels ab Seite 28. Denn das Jonglieren mit verschiedenen Aufgaben zur gleichen Zeit lässt den psychischen Druck steigen und die Konzentrationsfähigkeit sinken. Im schlimmsten Fall führt die permanente Anspannung sogar zu einem höheren Risiko für Herzinfarkt und Depressionen. Lassen Sie es also gar nicht so weit kommen. Setzen Sie Prioritäten und schaffen Sie sich regelmäßig Ruheinseln, auf denen Sie entspannt Ihre Aufgaben nacheinander erledigen können. Oder machen Sie es wie unser Knabe rechts: Atmen Sie tief durch und lassen Sie öfter mal die Seele baumeln!

Einen entspannten Sommer wünscht Ihnen
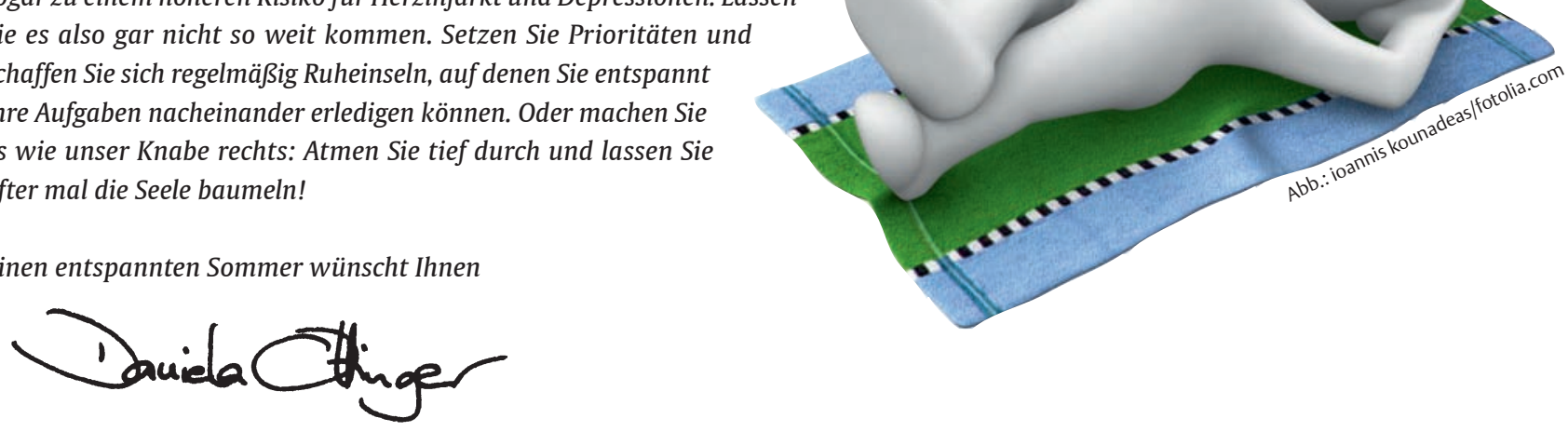